\title{
Effect of health education about personal hygiene on student's health in primary school
}

\author{
Amira YAHIA ${ }^{1}$, Abdalbasit MARIOD $^{2}$
}

\begin{tabular}{|c|c|}
\hline & ABSTRACT \\
\hline $\begin{array}{r}\text { Corresponding Author } \\
\text { Amira Yahia } \\
\text { DoI } \\
\text { https://10.48121/jihsam.863751 } \\
\text { Received } \\
18.01 .2021 \\
\text { Accepted } \\
\text { 10.04.2021 } \\
\text { Published Online } \\
30.04 .2021\end{array}$ & $\begin{array}{l}\text { The students' knowledge of personal hygiene can } \\
\text { implement by teachers in schools or parents at home. The } \\
\text { study was conducted in Khartoum State Sudan } 2012 \text { to } \\
\text { assess the effect of health education about personal } \\
\text { hygiene on student's health through the interventional } \\
\text { program. A quasi-experimental study pre-post-test design } \\
\text { was used in this study. Population of this study is students } \\
\text { level six with sample size } 356 \text { students. Previous of the } \\
\text { using of intervention program, E-histolytica notice was } \\
\text { higher in the control group } 20 \text { (69\%), giardia lamblia } 9 \\
\text { (29 \%) in the interventional group, while after the } \\
\text { intervention program, giardia lamblia } 23 \text { (22.1\%) in the } \\
\text { interventional group rate decreased. There was a } \\
\text { statistically significant difference after participants } \\
\text { received health massages and practice hand washing } \\
\text { technique (p-value =0.039). The score of personal hygiene } \\
\text { and the student's awareness of health messages increased } \\
\text { (p=<0.01). This study confirmed that the effect of health } \\
\text { education was highly significant among participants after } \\
\text { the intervention program. The study concluded that raising } \\
\text { awareness of students about personal hygiene to decrease } \\
\text { health problems associated with poor personal hygiene can } \\
\text { be provided through health education massages in } \\
\text { collaboration with the Ministry of Health and the Ministry } \\
\text { of Education. }\end{array}$ \\
\hline
\end{tabular}

${ }^{1}$ Assisstant professor, Department of Nursing, College of Applied Medical Sciences, Majmaah University, Al-Majmaah 11952, Saudi Arabia. amiraboshra@gmail.com.Orcid:0000-0003-4498-370X

2 Prof. Dr, College of Sciences and Arts-Alkamil, University of Jeddah, Alkamil, Saudi Arabia. basitmariod58@gmail.com. Orcid:0000-0003-32377948 


\section{INTRODUCTION}

Students' knowledge of hygiene is reflected to be provided by parents or schools. It is something with a direct effect on health and is related to sociocultural factors. Primary care showed a vital role in health education and promotion, so concentrating on hygiene habits is part of primary prevention(Barata \& Maricoto, 2019). Ministry of Health, Khartoum State, Sudan has started school health as a unit of Primary Health Care (PHC) in 1994, the goal at that time vaccination against meningitis for students in school, the program was developed and it is the structure was completed in 1996. The program covers all governmental basic and higher schools, including private in 2001. The last screening in 2010, was shown, that the most common problems, dental carriers (12.8\%), malnutrition (9\%), psychological disorders (6.4\%), and other health problems (16.2\%)(Boshra et al., 2017).

A cross-sectional study was conducted for 1008 students from the 6th to 12th class of governmental schools in Bikaner. The result revealed that more than $90 \%$ of the students know about personal hygiene, clothes, and oral hygiene, $46 \%$ of them are using toilet paper, and $29.8 \%$ for a sanitary pad. More than $90 \%$ bath, brush teeth every day, hand washes before a meal and after using the toilet. Less than $70 \%$ hand wash after handling the animal and cutting their nails, the school was the major source of knowledge for the students $(71 \%)$ (Shekhawat et al., 2019). In the cross-sectional study that was conducted among students at Dona Berber primary school, the result shows that among 359 participants $(65.5 \%)$ were infected with one or more types of intestinal parasites. The highest prevalence of parasites identified in the study was E. histolytica (24.5\%), followed by hookworm (22.8\%) (Hailegebriel, 2017).

A cross-sectional observational design was conducted in Chetla and Kolkata. The result reveals that $(74.04 \%)$ of the students complaining of health problems are associated with poor personal hygiene. The most common problem informs by the students $(56.73 \%)$ was diarrhea, followed by the passage of worms in their stool (45.19\%)(Sarkar, 2013).

A longitudinal, prospective study was conducted in Portugal, the results revealed that in both schools, there were significant differences in the pre-, and post-intervention at moments. In the "Paulo da Gama" school group, the means increase 0.65 points, with a statistical significance $(\mathrm{P}<0.05$, independent samples t-test) (Barata \& Maricoto, 2019).

In the "Pedro Eanes Lobato" school group, the average increase of 0.87 points, being also statistically significant $(\mathrm{P}<0.05$, independent samples t-test) and slightly higher than in the other school group. A cross-sectional study has been conducted in Bure Town, the result revealed that an intestinal parasitic infection was not significantly related to mothers' and fathers' educations, jobs, and family size $(\mathrm{P}>0.05)$. The rate of intestinal parasite infection was significantly higher among participants who had poor knowledge about hygiene, healthy food, and environmental sanitation (48.3\%) than those who had good knowledge (31.1\%) $(\mathrm{P}<0.05)$. The prevalence of protozoan infection was $(29.8 \%)$, helminths $(11.9 \%)$ and assorted infection (2.3\%) Seven type of intestinal parasites identified, Entamoeba histolytica $(22.1 \%)$ highest prevalent, followed by Giardia lamblia (8.6\%), Hookworms $(6.8 \%)$ and Ascaris lumbricoides (3.7\%). Hymenolepis nana, Trichuris Trichiura an and Taenia species rare prevalence $(<1 \%)$ (Sitotaw1 \& Yezina Gebeyaw, 2020).

Concern information on screening 2010, a recent study has been conducted to assess the quality of school health education on acquiring students' knowledge and increase awareness on personal hygiene through the interventional program.

\section{MATERIALS AND METHODS}

\subsection{Study site}

The study was conducted on 2012 in an Omdurman locality on public primary schools in Khartoum State, according to selection criteria randomly we found only seven schools meet the criteria with urban and rural schools which, include a total of 1182 students.

\section{Study design:}

An interventional quasi-experimental study with control group, the pre-post-test design was used in this study. With the use of a well-constructed questionnaire self-fill and stool examination. 


\subsection{Respondent sample}

Participants of this study level six in governmental primary schools who enrolled in an Omdurman locality primary schools, there was a total of approximately 1182 students. A simple random sampling procedure was used. 356 students met the criteria and was selected for this study, 178 students to the intervention group, and 178 was selected for the control group.

\subsection{Intervention}

The assessment of the students' knowledge was done by pre-test to the intervention and control group using questionnaires that were distributed and filled by students, which includes knowledge about personal hygiene, healthy food, and prevention of communicable diseases in addition to stool examination by microscopic. Then the training program was conducted bout handwashing using soap and water and how to brush the teeth in the interventional group. After three months of the interventional program, follow-up was done by posttest for collecting data through questionnaires and stool examination.

\subsection{Data management}

This study was conducted in different primary schools, with data collected personally by the researcher. Manual coding was used to check for any errors in coding. The coding manual and dummy tables were developed before entering the data. Double-entry of data by the researcher was done to prevent potential data entry errors. The data were checked and cleaned by performing preliminary frequency distribution to enhance accuracy and reliability. Data were analysed by the computerized method Statistical Package for the Social Sciences (SPSS) version 17. The descriptive statistics included frequencies, means, and standard deviations. Health educations knowledge score was compared between study and control groups. Different statistical analyses was done to test statistically significant differences such as chisquare test, independent samples t-test, one-sample t-test.

\section{Ethical considerations}

Ethical approval granted from the University of Medical Sciences and Technology and Research Ethics Committee (UMST IRB00008867), Ministry of Educations, Omdurman locality, and Managers of schools, the informed consent form was signed by managers on behave of the students and their families after students explain to them.

\section{RESULTS}

Three hundred and fifty-four (354) level six students have participated in the per-test. Results show all groups practice handwashing before and after meal and after using toilet and there was no significant differences in handwashing before meal, $(\mathrm{p}=0.079)$ and after toilet, $(\mathrm{p}=0.044)$. After posttest, there was a significant difference in the practice, and knowledge of the study group raised.
The results showed that there was a highly significant different in study group at follow up $(100 \%)$ vs. $(88.5 \%)$ handwashing before meal in control group $(97.9 \%$ vs $79 \%)$ after meal , and $(94.4 \%$ vs $57.3 \%)$ after toilet $(\mathrm{p}=<0.01)$. Knowledge about hand washing before and after intervention in primary schools is shown in Table 1.

Table 1 Knowledge about hand washing before and after intervention in primary schools

\begin{tabular}{|c|c|c|c|c|c|c|c|c|c|c|}
\hline \multirow{3}{*}{$\begin{array}{l}\text { Items: Hand washing } \\
\text { at pre- test }\end{array}$} & \multicolumn{4}{|c|}{ Study group $(n=178)$} & \multicolumn{4}{|c|}{ Control group $(n=176)$} & \multirow{3}{*}{$\begin{array}{l}\text { Chi- } \\
\text { square }\end{array}$} & \multirow{3}{*}{$\mathbf{p}$} \\
\hline & \multicolumn{2}{|c|}{ No } & \multicolumn{2}{|c|}{ Yes } & \multicolumn{2}{|c|}{ No } & \multicolumn{2}{|c|}{ Yes } & & \\
\hline & $\mathbf{n}$ & $\%$ & $\mathbf{n}$ & $\%$ & $\bar{n}$ & $\%$ & $\mathbf{n}$ & $\%$ & & \\
\hline Before meal & 32 & 18 & 146 & 82 & 20 & 11.4 & 156 & 88.6 & 3.09 & .079 \\
\hline After meal & 77 & 43.3 & 101 & 56.7 & 40 & 22.7 & 136 & 77.3 & 16.85 & $<0.01$ \\
\hline After toilet & 102 & 57.3 & 76 & 42.7 & 82 & 46.6 & 94 & 53.4 & 4.07 & .044 \\
\hline $\begin{array}{l}\text { Hand washing at } \\
\text { post-test: }\end{array}$ & \multicolumn{4}{|c|}{ Study group $(n=144)$} & \multicolumn{4}{|c|}{ Control group $(n=157)$} & & \\
\hline Before meal & 0 & 0 & 144 & 100 & 18 & 11.5 & 139 & 88.5 & 17.56 & $<0.01$ \\
\hline After meal & 3 & 2.1 & 141 & 97.9 & 33 & 21 & 124 & 79 & 25.57 & $<0.01$ \\
\hline After toilet & 8 & 5.6 & 136 & 94.4 & 67 & 42.7 & 90 & 57.3 & 55.32 & $<0.01$ \\
\hline
\end{tabular}


Table 2. Proper hand washing method among the group before and after intervention

\begin{tabular}{|c|c|c|c|c|c|c|c|c|c|c|}
\hline \multirow[b]{3}{*}{ Item } & \multicolumn{4}{|c|}{ Intervention Group } & \multicolumn{4}{|c|}{ Control Group } & \multirow{3}{*}{$\begin{array}{c}\text { Chi- } \\
\text { square }\end{array}$} & \multirow[b]{3}{*}{ p } \\
\hline & \multicolumn{2}{|c|}{ Yes } & \multicolumn{2}{|c|}{ No } & \multicolumn{2}{|c|}{ Yes } & \multicolumn{2}{|c|}{ No } & & \\
\hline & $\mathbf{n}$ & $\%$ & $\mathbf{n}$ & $\%$ & n & $\%$ & $\mathbf{n}$ & $\%$ & & \\
\hline Pre-test & 0 & 0.0 & 178 & 100.0 & 0 & 0.0 & 178 & 100.0 & & \\
\hline Post- test & 120 & 82.0 & 26 & 18.0 & 0 & 0.0 & 157 & 100.0 & & $<0.01$ \\
\hline
\end{tabular}

Three hundred and fifty-six (356) level six students have participated in the pretest results show all groups did not perfectly practice the proper handwashing method $(0.00 \%)$. Three hundred and three (303) students (146) in the study and (157) in the control group participated the post-test. Chi-square test was used to test whether the proportions of participants were equal values. The results showed highly significant different in study group at follow up $(82.2 \%$ vs $0.0 \%)$ in control group, $(\mathrm{p}=<0.01)$. Proper handwashing method among the group before and after the intervention is shown in Table 2.

\subsection{Stool examination of the students.}

Sample of a total of 60 students, 31 in the intervention, and 29 in the control group stool was examined in pre-test for E-histolytica, Giardia lamblia, motile bacteria, and others. The result shows that no statistically significant difference between the group in the pre-test, normal stool was seen similar in the two groups (1 (3.2\% vs.1 (3.4\%), E-histolytica notice was higher in the control group 20 (69\%), giardia lamblia $9(29 \%)$ in the intervention, $(\mathrm{p}=0.068)$. After six months of intervention, a sample of (212) students in the intervention (104) and (108) in the control group another stool examination done the result shows that there was statistically significant difference. The normal stool was seen $1(1 \%)$ in the study group, giardia lamblia $23(22.1 \%)$, vs.23 (21.3\%) in the control group, Entamoeba histolytica $9(8.3 \%)$ in the control group. Motile bacteria were seen higher in the control group 76 (70.4\%), and 1(1\%) Hymenolepis nana worm notice in the study group, ( $\mathrm{p}=0.039$ ). Figures show the result of stool examination before and after the intervention.

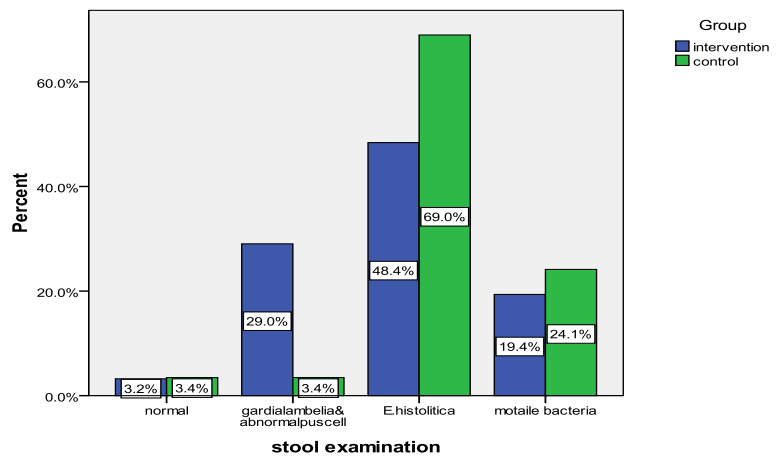

Stool examination of the students in public primary schools at pre-test is shown in Figure 3.1

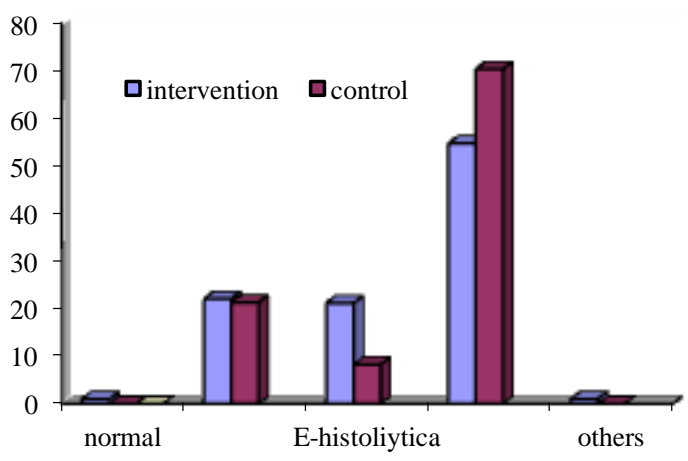

Bar Stool examinations of students in public primary schools at post-test is shown in Figure 3.2.

\subsection{Personal hygiene}

A sample of total 353 participants in the pre-test, 178 in the intervention, and 175 in the control group was examined. The result shows that the test was not statistically significant $(\mathrm{t}(-.589)=351, \mathrm{p}=0.556$, and (Mean= 8.39, SD =3.37), but lower than control group $($ Mean $=8.60, \mathrm{SD}=3.41)$. The $95 \%$ confidence interval for the means ranged from 0.921 to 0.497 . After six months the test was statistically significant $(\mathrm{t}(298)=9.97, \mathrm{p}=<0.01)$. The result supported research hypothesis, students in study group mean and standard deviation (Mean= $12.42, \mathrm{SD}=2.35$ ), was higher than the control group $($ Mean $=9.12, \mathrm{SD}=3.26)$. The $95 \%$ confidence 
interval for the difference in means range from 2.65 to 3.93 . The eta square index indicates that $(33 \%)$ of the variance of personal hygiene knowledge scores accounted for by whether students assign to the study or control group.

The personal hygiene score includes the frequency of taken a bath /day, washing hands before and after meals, using the toilet, and brushing teeth/day. The results reveal that in the post-test the study group, $68.1 \%$ taken a bath more than once /day, washing their hands before meal $100 \%$, and after $97.9 \%, 88.5 \%$ before the meal, and $79 \%$ after in the control group, washing hands after using toilet $94 \%$ in the study group and $57.3 \%$ in the control group. $71.5 \%$ was brushing teeth more than once /day in the study. The figure shows the distribution of the pre and post-test mean score.

Figure 3.3: Error bar (Two standards deviation above and below the mean) for personal hygiene score for study and control group at pre-test.
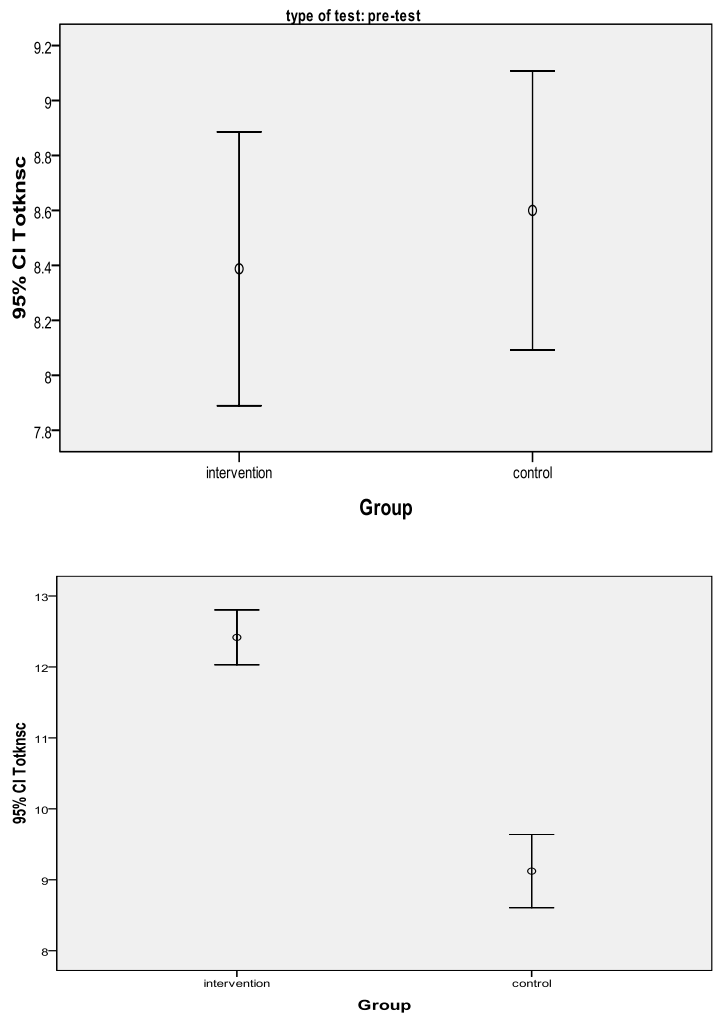

Error bar in post-test (Two standards deviation above and below the mean) for personal hygiene score for study and control group is shown in Figure 3.4 .

\subsection{Health education}

The test was statistically significant $(\mathrm{t}(355)=-$ $4.37 \mathrm{p}<=0.01)$, mean and standard deviation (Mean=13.72, SD = 5.54), was lower than control group $($ Mean $=16.56, \mathrm{SD}=6.65)$, the $95 \%$ confident interval for the means ranged from -4.12 to -1.56 . The eta square index indicated that $14.3 \%$ of the variance of students in the control group has a high knowledge score in health education; compared to the study group at the pre-test. After intervention the result shows that test was statistically significant $(\mathrm{t}(299)=15.41 \mathrm{p}<=0.01$, mean and standard deviation $($ Mean=27.59, SD = 2.87), was higher than in the control group (Mean $=18.85, \mathrm{SD}=6.22$ ), the $95 \%$ confident interval the means from 7.65 to 9.82 . Chi-square test used to test physical activities, and the prevention of communicable diseases, the test was statistically significant, (chi-square test $=(1, \mathrm{n}=$ $(303)=8.40$, p 0.004 at post-test.

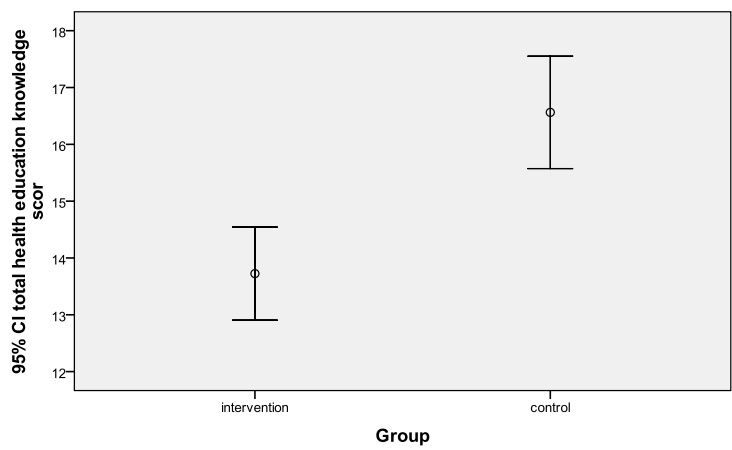

Error bar. (Two standards deviation above and below the mean) for health education knowledge score for intervention and control group in pre-test is shown in Figure 3.5.

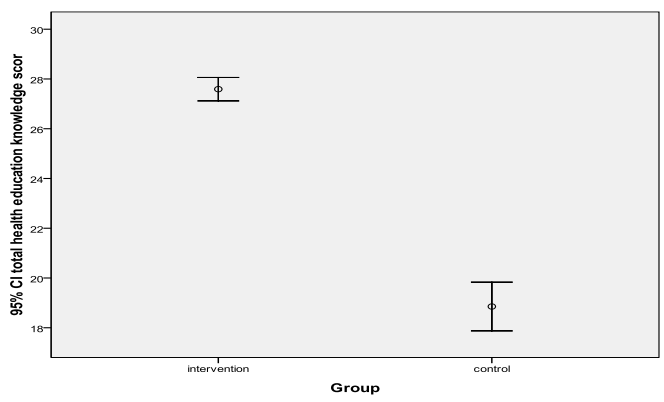

Error bar. (Two standard deviation above and below the mean) for health education knowledge score for study and control group at post-test is shown in Figure 3.6. 


\section{DISCUSSION}

A recent study shows that participants in the study group their knowledge and practice of perfect hand washing methods rising $100 \%$ washing their hands before and after the meal while the control group $88.5 \%$ before and $79 \%$ after a meal $94 \%$ of the study group washing hands after using the toilet.

Compare to the study done in Gombang Mlati Sleman, Yogyakarta showed similar results p-value of 0.001 , which means that there is an effect of health education on handwashing techniques in students of State Primary School by raising student awareness about handwashing by using the Wilcoxon test. (Effect et al., 2020)

Recent study results show that the intervention program implements by the researcher in the schools, which aims to enhance and increase student awareness of hygiene to prevent communicable diseases and improve student's performance. Before the intervention, no statistically significant difference was found between the groups ( $\mathrm{p}=0.068$ ). The assessment followed intervention shows that an interventional group has a less intestinal parasitic infection than the control group, statistically, significance was seen, $(p=0.039)$. Students' health status improves as a result of health education. The most common intestinal parasite seen between the students were giardia lamblia, Entamoeba, and rare cases of Hymenolepis nana worm.

Regarding personal hygiene awareness, the study result shows that the test was not statistically significant $(\mathrm{t}(.589)=351, \mathrm{p}=0.556)$ before the intervention. After six months of intervention second assessment, the test was statistically significant $(\mathrm{t}$ $(298)=9.97, p=<0.01)$ the result was supported research hypothesis, students in study group mean and standard deviation (Mean= 12.42, $\mathrm{SD}=2.35$ ), higher than the control group $($ Mean $=9.12, \mathrm{SD}=$ 3.26). The students in the interventional group frequently have taken a bath more than once a day, washing hands before and after meals, when using the toilet, and brushing teeth more than once/day. These indicate that health education is effective can be used as a method of health promotion in the school setting.

The result of a recent study shows that the test was statistically significant $(\mathrm{p}<=0.01$ ), which indicates that the students have health education messages. After the intervention, the test was statistically significant $(\mathrm{p}<=0.01)$, the means increase in the intervention group than the control. The result reveals the importance of initiating health education messages in the curriculum of primary school education to increase students' awareness through the cooperation of the ministry of health and education.

Compared to other studies, a qualitative study, conducted, the result shows statistically significant there was an increase in knowledge and personal behaviour after the intervention ( $7.22 \pm 1.34$ preintervention to $7.70 \pm 0.74$ post-intervention and $9.75 \pm 2.98$ pre-intervention to $12.16 \pm 2.12$ postintervention, respectively, $\mathrm{p}<0.001$ ). These similar to the recent study despite using different study design(Widyasari et al., 2020) .

In a pre-experimental study, the result shows that the mean pre-teaching knowledge score was $8.13 \pm 2.4$, and the post-teaching knowledge score was $9.93 \pm 2.3$. He tests the significant pre and posts mean by using paired t-Test, and the value is -8.69 ( $p=<0.001)$ statistically significant reveals that the use of video effective in assisting teaching and demonstration. The difference from the recent study the author uses a video to make the student more focused on health messages (David et al., 2020).

The study results revealed that an intestinal parasitic infection higher among the participants who had poor knowledge of hygiene, healthy food, and environmental health. Most identified types of intestinal parasites Entamoeba histolytica, Giardia lamblia, and fewer of Hymenolepis nana. These similar to the recent study that used microscopic machines for stool examination differ in study design (Sitotaw1 \& Yezina Gebeyaw, 2020).

Similar results form a cross-sectional study conducted in Khartoum State, the result showed that the frequency of intestinal parasites was $35.5 \%$ of total students examined, females, affected more than males $(38.8 \%$ and $32.8 \%$, correspondingly). The intestinal parasite was Taenia spp. (1.5\%) followed by Giardia lamblia (3.7\%), Schistosoma mansoni and Ascaris lumbricoides (5.2\% each), Entamoeba coli (7.5\%), Hymenolepis nana (10.4\%), and Entamoeba histolytica (16.4\%). In total, $20.9 \%$ were infected with a single parasite, while $14.9 \%$ were infected with more than one parasite (Abdalazim Hassan et al., 2020).

Compared to the previous cross-sectional study was conducted in Sudan to evaluate the prevalence of intestinal parasite infection among school children. The result reveals that the overall prevalence was $56.9 \%$ (144/253), and found that the common types of intestinal parasites between the school children were E. histolytica 31.2\% (79/253), 
G. lamblia $22.9 \%(58,253)$, and H. nana $2.8 \% \quad(7,253)$ (Suliman et al., 2019).

\section{CONCLUSION}

This study has confirmed that there is a significant difference among participants after the intervention program. The study concluded that raising awareness of students about personal hygiene to decrease health problems associated with poor personal hygiene could be provided through health education massages in collaboration with a ministry of health and education.

\section{Acknowledgments}

I would like to thank the School Health Department in Khartoum State Ministry of Health for help in term of providing me all information about the school health program.

I would like to thank the staff of the AboSead health center for helping me in the student's investigation, especially lab technicians Hossam, Asia, and Safa,

My thanks to all managers and participants in a school setting for co-operation and help during the data collection and training program.
Conflict of Interest: The authors whose names are listed below, certify that they have no affiliations with or involvement in any organization or entity with any financial (such as honoraria; educational grants; participation in speakers' bureaus; membership, employment, consultancies, stock ownership, or other equity interest; and expert testimony or patentlicensing arrangements) interest, or non-financial (such as personal or professional relationships, affiliations, knowledge or beliefs) interest in the subject matter or materials discussed in this manuscript.

i.e: The authors declare that they have no conflict of interest.

\section{Ethical considerations}

Ethical approval granted from the University of Medical Sciences and Technology and Research Ethics Committee (UMST IRB00008867), Ministry of Educations, Omdurman locality, and Managers of schools, the informed consent form was signed by managers on behave of the students.

Funding: No any financial support.

\section{REFERENCES}

Abdalazim Hassan, H., Abd Alla, A. B., Elfaki, T. E. M., \& Saad, M. B. E. A. (2020). Frequencies of gastrointestinal parasites among students of primary school in Al Kalakla Locality, Khartoum State, Sudan: A cross-sectional study. F1000Research, 8. https://doi.org/10.12688/f1000research.20610.3

Barata, A., \& Maricoto, T. (2019). Teaching children about hygiene: A primary prevention experience in Portugal. Journal of Family Medicine and Primary Care, 8(3), 1017. https://doi.org/10.4103/jfmpc.jfmpc_428_18

Boshra, A., Abdalla, S. M., \& Mohamed, E. Y. (2017). Effect of Innovative School Health Program on the Student 'S Effect of Innovative School Health Program on the Student' S Nutritional Status in Basic Schools in Khartoum State 2011-2012. 3(March), 51-56. https://doi.org/10.20959/wjpps20173-8768

David, M. M., Sujitra, V., Arulmozhi, E., \& Navaneetha, D. M. (2020). Effectiveness of Video Assisted Teaching and Demonstration on Knowledge Regarding Personal Hygiene Among School Children. International Journal of Innovative Science and $\begin{array}{llll}\text { Research Technology, } & \text { 5(7), }\end{array}$ https://doi.org/10.38124/ijisrt20jul856

Effect, T. H. E., Health, O. F., On, C., In, T., \& Schools, P. (2020). Indonesian Journal of Global Health Research. Indonesian Journal of Global Health Research, 2(3), 217-224. https://doi.org/10.37287/ijghr.v2i4.250

Hailegebriel, T. (2017). Prevalence of intestinal parasitic infections and associated risk factors among students at Dona Berber primary school, Bahir Dar, Ethiopia. BMC Infectious Diseases, 17(1), 1-8. https://doi.org/10.1186/s12879-017-2466-x

Sarkar, M. (2013). Personal hy giene among primary school children living in a slum of Kolkata, India. Journal of Preventive Medicine and Hygiene, 54(3), 153-158. https://doi.org/10.15167/24214248/jpmh2013.54.3.401

Shekhawat, R., Sodha, V. S., Sharma, N., \& Verma, M. (2019). Knowledge and practice regarding personal hygiene among students of government schools of Bikaner, Rajasthan. International Journal of Advanced Community Medicine, 2(2), 108-111. https://doi.org/10.33545/comed.2019.v2.i2b.15

Sitotaw1, B., \& Yezina Gebeyaw. (2020). 1,*, 23 2. 13(June), 131-146.

Suliman, M. A., Tamomh, A. G., Magboul, A. M., Mohammed, H. Y., Bakhit, H. A., Altoum, S. A., \& Ahmed, S. M. (2019) Prevalence of Intestinal Parasitic Infections and Associated Risk Factors among School Children in White Nile State, Sudan Toxoplasmosis View project schistosomiasis View project Prevalence of Intestinal Parasitic Infections and Associated Risk Factors am. Journal of Infectious Disease and Diagnosis, 4(1), 811. https://doi.org/10.4172/2576-389X.1000125

Widyasari, V., Widyasari, V., Prabandari, Y. S., \& Utarini, A. (2020). Training intervention to improve hygiene practices in Islamic boarding school in Yogyakarta, Indonesia: A mixed-method study. PLoS ONE, $15(5 \quad$ May), 1-13. https://doi.org/10.1371/journal.pone.0233267 